\title{
Human resource assessment of academic urology across Canada: What are the future job prospects?
}

\author{
Bassel G. Bachir, MD; ${ }^{*}$ Armen G. Aprikian, MD, FRCSC; ${ }^{*}$ Sidney B. Radomski, MD, FRCSC; ${ }^{\dagger}$ \\ Wassim Kassouf, MD, FRCSC ${ }^{*}$
}

"Department of Surgery, Division of Urology, McGill University, Montreal, QC; 'Department of Surgery, Division of Urology, University of Toronto, Toronto, ON

Cite as: Can Urol Assoc J 2013;7(5-6):162-6. hitp://dx.doi.org/10.5489/cuaj.198

\section{Abstract}

Introduction: Our objective was to capture an overview of anticipated staffing needs at Canadian urology academic centres over the next 5 years to help guide and counsel urology residents in their respective programs.

Methods: A 30-question survey was sent by email to all chairmen of academic urology divisions/departments during fall 2012. The first part of the survey solicited basic demographic information regarding number of residents, number of fellows and fellowships, and number of attending staff and affiliated hospitals. The second part of the survey included detailed questions on the number and sub-specialty of urologists needed at each respective institution, as well as the appropriate year of recruitment.

Results: The response rate was $100 \%$. There are 13 urology training programs across Canada located in 6 out of the 10 provinces. Robotic surgery is available at 9 out of the 13 centres. A total of 68 urologists need to be recruited by academic institutions throughout Canada within the next 5 years. The greatest need is for general urologists, with a total of 13 required. This is followed by 12 urologic oncologists needed, 11 female urology, 7 reconstructive urologists, 6 pediatric urologists, 6 endourologists, 5 transplant surgeons, 4 infertility/andrology, and 4 experts in advanced laparoscopy/robotics. There was no need for any urologic trauma surgeons in any academic institution surveyed.

Conclusions: A total of 68 urologists need to be recruited into academic urology across Canada within the next 5 years. This crucial information can be used to help guide urology residents in choosing the most appropriate fellowship, in addition to providing them with an overview of future job prospects at academic institutions throughout the country.

\section{Introduction}

One of the most daunting aspects of graduating from a residency program is finding the most appropriate fellowship and, subsequently, the most suitable job. In Canada, where there are a limited number of academic centres of excellence, this can be more challenging as physicians may be required to work in underserved or rural areas that may not live up to their expectations. Therefore, it is crucial that physicians-in-training become aware of possible future job prospects to help them decide and better prepare themselves for the job market. Furthermore, identifying anticipated staffing needs is crucial, as any shortage may negatively affect both the quantity and quality of health care provided. Establishing a proper balance in future staffing practices is particularly important, as recent evidence suggests that Canada's healthcare system is in economic disequilibrium, ranking last in the 30 country Euro-Canada Health Consumer Index. This was mainly due to the long wait times that Canadians face to get much needed care. ${ }^{1}$

For this reason, to capture an accurate picture of anticipated staffing needs over the next 5 years and to help guide and counsel urology residents in their respective programs, we conducted a survey of Canadian academic urology centres regarding staffing and employment. We have compiled this information to help prioritize and balance workforce recruitment efforts.

\section{Methods}

A 30-question survey was sent by email to all chairmen across the 13 academic urology divisions/departments during fall 2012. The surveyed institutions included: University of Toronto, McMaster University, Western University, Queen's University and Ottawa University in Ontario; McGill University, University of Montreal, University of Sherbrooke and Laval University in Quebec; University of British Columbia, University of Alberta, and University of Manitoba in the West and Dalhousie University in the East. The first part of the survey solicited basic demographic information regarding number of residents, number of fellows and fellowships, and number of attending staff and 
affiliated hospitals. The second part of the survey included detailed questions on the number and sub-specialty of urologists needed at each respective institution, as well as the appropriate year of recruitment. Data were then compiled into one combined database for final analysis. To maintain anonymity, yet keep the information useful to all concerned, the results were aggregated and reported by region. Ontario universities were one region; Quebec was another region and the other 4 universities were considered "Other."

\section{Results}

The response rate was $100 \%$. There are 13 urology training programs across Canada located in 6 of the 10 provinces. There are 5 programs in Ontario, 4 in Quebec, and 1 each in British Columbia, Alberta, Manitoba and Nova Scotia. In general, there are more male residents, with the female to male ratio ranging from 0 (Queen's) to $77.7 \%$ (Western). Fellowships are offered at all the academic centres, except Queen's, Sherbrooke and Manitoba, with urologic oncology as the most common fellowship on offer. Interestingly, although the total number of male attending staff in all institutions is 180 , the total number of female attending staff in all institutions is only 15 , with $50 \%$ of them at 2 centres (University of Montreal and Manitoba) (Table 1). All centres have at least 3 affiliated hospitals, except Sherbrooke with 1. Robotic surgery is available at 9 of the 13 centres (Table 2). Only 4 of the 13 chairmen agreed that there was a shortage of urologists in their province. Out of the 5 chairmen in Ontario, only 2 agreed that there was a shortage of urologists in their province. Out of the 4 chairmen in Quebec, only 1 agreed that there was a shortage of urologists in their province. Of the remaining 4 provinces, the only shortage was identified in Alberta.

Nine out of the 13 chairmen agreed that they had the capacity to recruit more attending staff (4 Quebec, 3 Ontario, 2 Other). Only 3 chairmen agreed that they had the capacity to increase the number of residents in their program (2 Quebec and 1 Other). In addition, only 5 agreed that they had the capacity to recruit more fellows into their respective divisions (3 Ontario, 1 Quebec and 1 Other).

We then asked the chairmen about their need for urologists with the following training: pediatric urology, urologic oncology, reconstructive urology, female urology, advanced laparoscopy/robotics, endourology, urologic trauma surgeons, infertility and/or andrology, transplant surgeons and general urology. They all identified a need for more urologists in their respective programs within the next 5 years. Unexpectedly, in Canada, the greatest need in academic institutions is for general urologists, with a total of 13 required in 4 different provinces. This is followed by urologic oncologists, where a total of 12 are required in 5 different provinces. Then comes female urology, where 11 are required in 5 provinces; 7 reconstructive urologists are needed in 4 provinces, whereas 6 pediatric urologists and 6 endourologists are needed each in 3 provinces. A need was identified for 5 transplant surgeons in 4 provinces, while 4 experts in advanced laparoscopy/robotics are needed in 3 provinces. Four infertility and/or andrology attending staff are needed in 3 provinces, and finally, there was no need for any urologic trauma surgeons in any academic institution surveyed (Fig. 1). This is a total of 68 urologists that need

Table 1. Basic demographic information across centres

\begin{tabular}{|c|c|c|c|c|c|c|c|c|c|}
\hline University & Province & $\begin{array}{c}\text { Male } \\
\text { residents }\end{array}$ & $\begin{array}{l}\text { Female } \\
\text { residents }\end{array}$ & No. fellows & $\begin{array}{c}\text { No. } \\
\text { fellowships }\end{array}$ & $\begin{array}{c}\text { Male } \\
\text { attendings }\end{array}$ & $\begin{array}{c}\text { Female } \\
\text { attendings }\end{array}$ & $\begin{array}{c}\text { No. } \\
\text { hospitals }\end{array}$ & $\begin{array}{l}\text { Robotic } \\
\text { surgery }\end{array}$ \\
\hline Toronto & ON & 18 & 4 & 11 & 6 & 26 & 1 & 5 & Yes \\
\hline McMaster & ON & 13 & 1 & 2 & 2 & 13 & 0 & 6 & Yes \\
\hline Western & ON & 9 & 7 & 5 & 4 & 11 & 0 & 3 & Yes \\
\hline Queen's & ON & 6 & 0 & 0 & 0 & 8 & 0 & 4 & No \\
\hline Ottawa & ON & 16 & 1 & 3 & 3 & 15 & 0 & 4 & Yes \\
\hline McGill & $\mathrm{QC}$ & 16 & 3 & 2 & 5 & 20 & 0 & 5 & Yes \\
\hline Montreal & $\mathrm{QC}$ & 7 & 4 & 1 & 2 & 21 & 4 & 3 & Yes \\
\hline Sherbrooke & $\mathrm{QC}$ & 3 & 2 & 0 & 0 & 5 & 1 & 1 & No \\
\hline Laval & $\mathrm{QC}$ & 10 & 6 & 1 & 1 & 13 & 2 & 4 & Yes \\
\hline British Columbia & $\mathrm{BC}$ & 12 & 3 & 3 & 2 & 15 & 2 & 4 & Yes \\
\hline Alberta & $A B$ & 8 & 2 & 1 & 1 & 16 & 1 & 4 & Yes \\
\hline Manitoba & MB & 8 & 2 & 0 & 0 & 7 & 3 & 3 & No \\
\hline Dalhousie & NS & 13 & 1 & 1 & 1 & 10 & 1 & 4 & No \\
\hline
\end{tabular}


Bachir et al.

\begin{tabular}{|c|c|}
\hline \multicolumn{2}{|l|}{ University } \\
\hline Toronto & $\begin{array}{l}\text { Oncology, Endourology/Robotic/ } \\
\text { Stones, Infertility, Neurourology/Female/ } \\
\text { Reconstructive, Functional, Pediatric }\end{array}$ \\
\hline McMaster & Laparoscopic, Transplant \\
\hline Western & $\begin{array}{l}\text { Endourology, Andrology, Oncology, } \\
\text { Transplant }\end{array}$ \\
\hline Queen's & None \\
\hline Ottawa & $\begin{array}{l}\text { Men's Health/Erectile Dysfunction, Oncology, } \\
\text { Pediatric }\end{array}$ \\
\hline McGill & $\begin{array}{l}\text { Neurourology/Female-Pelvic Reconstruction/ } \\
\text { Bladder Dysfunction, Pediatric, MIS/Robotics, } \\
\text { Infertility/Andrology, Sexual Medicine/ } \\
\text { Reconstructive }\end{array}$ \\
\hline Montreal & Oncology, Robotic \\
\hline Sherbrooke & None \\
\hline Laval & Oncology \\
\hline British Columbia & Oncology, Urogynecology \\
\hline Alberta & Transplant \\
\hline Manitoba & None \\
\hline Dalhousie & Neurourology/Noiding Dysfunction \\
\hline
\end{tabular}

to be recruited by academic institutions throughout Canada within the next 5 years (Fig. 2).

We also tallied the needs at academic institutions with urology training programs by region (Table 3). Protected time for nonclinical activities varied significantly among institutions and subspecialties. The regional breakdown is illustrated in Fig. 3a for Ontario, Fig. 3b for Quebec and Fig. 3c for the "Other" region.

\section{Discussion}

Using a structured email-based survey, we were able to assess the anticipated recruitment needs for academic urologists throughout Canada, potentially identifying shortages that need to be filled.

A total of 68 academic urologists will be needed in the 13 urology training programs across Canada within the next 5 years. The highest number $(n=25)$ will be required in Quebec. Surprisingly, the greatest need was for general urologists $(n=13)$.

The above results are encouraging in that a true need was identified across all institutions. However, we should keep in mind that this represents the urologists that will be needed for recruitment at academic institutions only, and does not capture the employment projections for community urologists. Hence, for Canada as a whole, there certainly is a need for more urologists than the 68 identified here. As an example, using a computer model based on an agreed ideal population-urologist ratio of 52234:1, in 1999, Pace and colleagues previously estimated that there would be
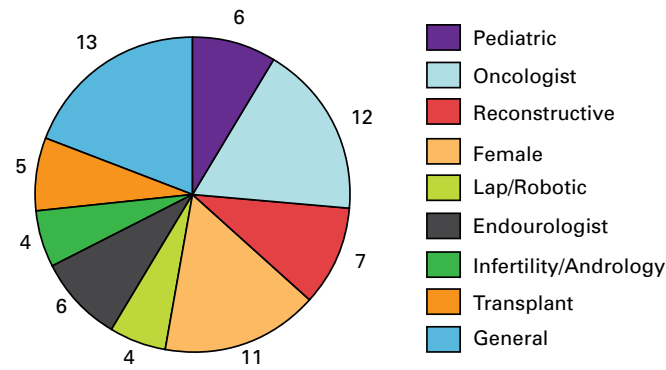

Fig. 1. Number and sub-specialty of urologists needed within the next 5 years.

a shortage of 101 urologists in Ontario in 2010 alone. $^{2}$ It would therefore be interesting to compile data on future job prospects at both academic and non-academic institutions, as well as in community practice across the provinces.

Moreover, it is likely that these projections represent what could be done in an ideal world, where chairmen have carte blanche on recruitment decisions. In reality, hospital economics and operating room time and space eventually determine when and which urologists may be recruited. Furthermore, in some provinces such as Quebec, the hospital positions are mandated by the government which may or may not be in line with the division's future projections. In addition and to further validate our results, we also sent out the exact same survey to the program directors at each institution. Our goal was to ascertain whether any discrepancies existed between chairmen projections and program director projections, and this was found to be the case (data not shown). Although in most instances the differences were minor, this nevertheless may highlight the need to potentially further improve communication between chairmen and their respective program directors concerning future job prospects to relay a consistent message to their residents.

Furthermore and similar to what has been done in the United States, ${ }^{3}$ an identical survey should be conducted within the next 5 to 10 years to compare trends and reassess recruitment needs. In their study involving 115 non-military accredited urology programs, Lightfoot and colleagues

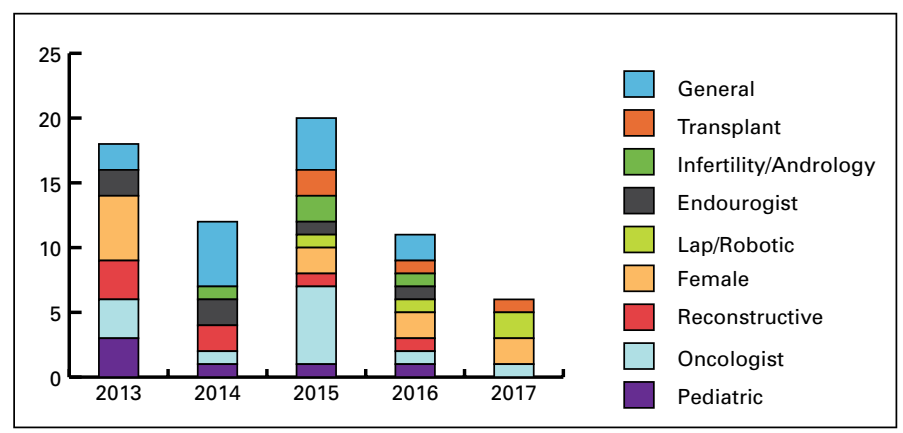

Fig. 2. Yearly distribution of urologists to be recruited at academic institutions in Canada over the next 5 years. Total is 67 because the year of recruitment is missing from data for transplant recruit from one institution. 


\begin{tabular}{|c|c|c|c|c|c|c|c|c|c|}
\hline & Pediatric & Onc & Recon & Female & Lap/Rob & Endo & Infert/Andro & Trans & Gen \\
\hline \multicolumn{10}{|l|}{ Ontario } \\
\hline No. recruits & 4 & 4 & 2 & 3 & 2 & 1 & 1 & 2 & 4 \\
\hline $\begin{array}{l}\text { Years of } \\
\text { recruitment }\end{array}$ & $\begin{array}{c}1 \text { in } 2013 \text {, } \\
2014,2015 \\
\text { and } 2016\end{array}$ & $\begin{array}{l}1 \text { in } 2013 \\
\text { and } 2014 ; \\
2 \text { in } 2015\end{array}$ & $\begin{array}{l}1 \text { in } 2015 ; \\
1 \text { in } 2016\end{array}$ & $\begin{array}{c}1 \text { in } 2013, \\
2016 \text { and } \\
2017\end{array}$ & 2 in 2017 & 1 in 2014 & 1 in 2016 & $\begin{array}{c}1 \text { in } 2017 \\
\text { and } 1 \\
\text { unknown }\end{array}$ & $\begin{array}{c}1 \text { in } 2014 \\
\text { and } \\
3 \text { in } 2015\end{array}$ \\
\hline $\begin{array}{l}\text { Protected } \\
\text { time (range) }\end{array}$ & $25-50 \%$ & $25-50 \%$ & $25-50 \%$ & $25-50 \%$ & $25 \%$ & $25 \%$ & $50 \%$ & $0-50 \%$ & $0-25 \%$ \\
\hline \multicolumn{10}{|l|}{ Quebec } \\
\hline No. recruits & 1 & 4 & 3 & 5 & 1 & 4 & 2 & 1 & 4 \\
\hline $\begin{array}{l}\text { Years of } \\
\text { recruitment }\end{array}$ & 1 in 2013 & $\begin{array}{l}1 \text { in 2013; } \\
2 \text { in } 2015 \\
1 \text { in } 2016\end{array}$ & $\begin{array}{c}2 \text { in } 2013 \\
\text { and } \\
1 \text { in } 2014\end{array}$ & $\begin{array}{l}2 \text { in } 2013 \\
2 \text { in } 2015 \\
1 \text { in } 2017\end{array}$ & 1 in 2016 & $\begin{array}{c}1 \text { in } 2013, \\
2014,2015 \\
\text { and } 2016\end{array}$ & 2 in 2015 & 1 in 2016 & $\begin{array}{l}1 \text { in } 2013 \\
1 \text { in } 2014 \\
2 \text { in } 2016\end{array}$ \\
\hline $\begin{array}{l}\text { Protected } \\
\text { time (range) }\end{array}$ & $25 \%$ & $25-50 \%$ & $25 \%$ & $25-50 \%$ & $25 \%$ & $25 \%$ & $25 \%$ & $50 \%$ & $0-25 \%$ \\
\hline \multicolumn{10}{|l|}{ Other } \\
\hline No. recruits & 1 & 4 & 2 & 3 & 1 & 1 & 1 & 2 & 5 \\
\hline $\begin{array}{l}\text { Years of } \\
\text { recruitment }\end{array}$ & 1 in 2013 & $\begin{array}{l}1 \text { in 2013; } \\
2 \text { in 2015; } \\
1 \text { in } 2017\end{array}$ & $\begin{array}{c}1 \text { in } 2013 \\
\text { and } 1 \text { in } \\
2014\end{array}$ & $\begin{array}{c}2 \text { in } 2013 \\
\text { and } \\
1 \text { in } 2016\end{array}$ & 1 in 2015 & 1 in 2013 & 1 in 2014 & 2 in 2015 & $\begin{array}{l}1 \text { in } 2013 \\
3 \text { in } 2014 \\
1 \text { in } 2015\end{array}$ \\
\hline $\begin{array}{l}\text { Protected } \\
\text { time (range) }\end{array}$ & $25 \%$ & $25-50 \%$ & $50 \%$ & $25-50 \%$ & $25 \%$ & $25 \%$ & $25 \%$ & $25-50 \%$ & $0 \%$ \\
\hline
\end{tabular}

found that the number of academic urologists needed in the U.S. increased from 203 in 1995 to 292 in $2010 .^{3}$ This is particularly important given the growing number of urology residents trained in Canada over the last several years. According to data from the Canadian Post-M.D. Education Registry, the number of urology trainees increased from 110 in 1994/95 to 166 in 2010/11, representing a 50\% rise. Therefore, accurately predicting recruitment needs is crucial to maintain a healthy balance of graduates and to avoid unnecessary over-production of specialists. ${ }^{4}$

It is rather surprising to find that in this age of specialization, the greatest need was for general urologists. This may contradict with what academic institutions traditionally want, which is research-oriented physicians that can bring in significant grants. However, this is not completely unexpected as general urology was identified as one of the most common sought-after urologic specialties in the U.S. in $2010{ }^{3}$

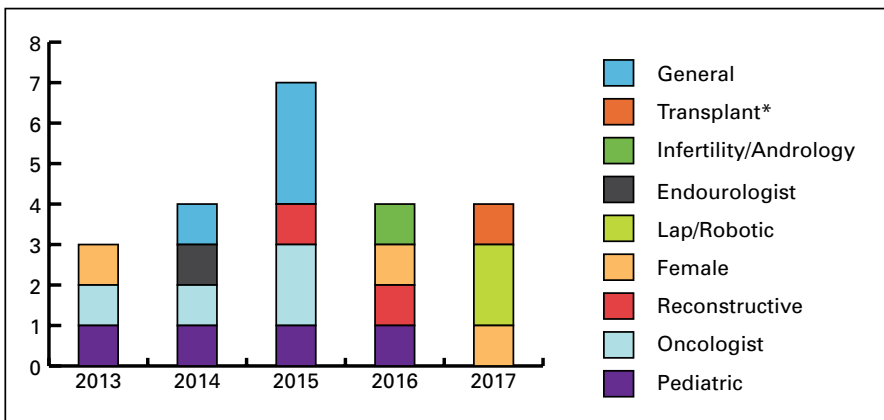

Fig. 3a. Anticipated recruitment needs in Ontario. *1 year unknown.
Furthermore, this data reaffirm the importance of general urologists, and dispel any concerns that post-residency fellowships are an absolute necessity. In addition, this begs the question of what exactly residents need to do following residency to occupy these general urology positions in academic hospitals. Would priority be given to fresh graduates, or is it more likely that experienced urologists would be preferred? If that is the case, should we advise residents to seek fellowships following residency or not? Should training programs be extended by 1 year to those interested to allow for more general urology exposure, perhaps increasing emphasis on clinical exposure rather than surgical training? Lastly, how can we entice a general urologist to work in an academic setting, or should we simply integrate general urology into the practice of any academic urologist trained in a subspecialty?

It is also not unexpected to find that within the next 5 years, there will be a great need for urologic oncologists

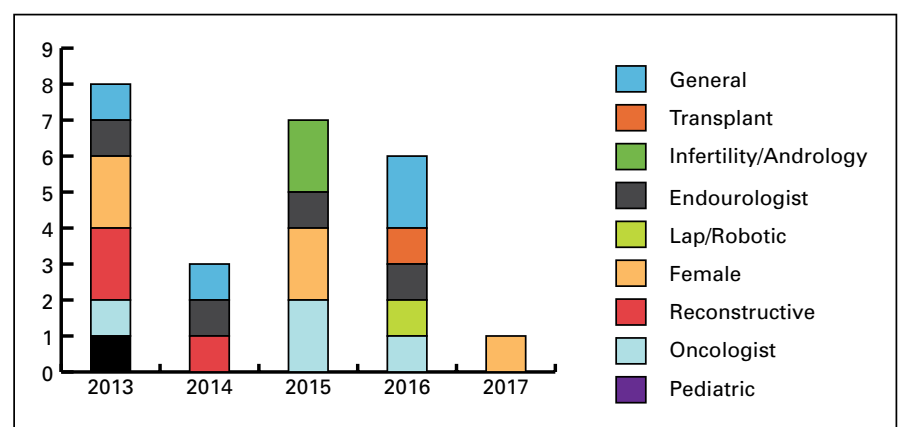

Fig. 3b. Anticipated recruitment needs in Quebec. 
Bachir et al.

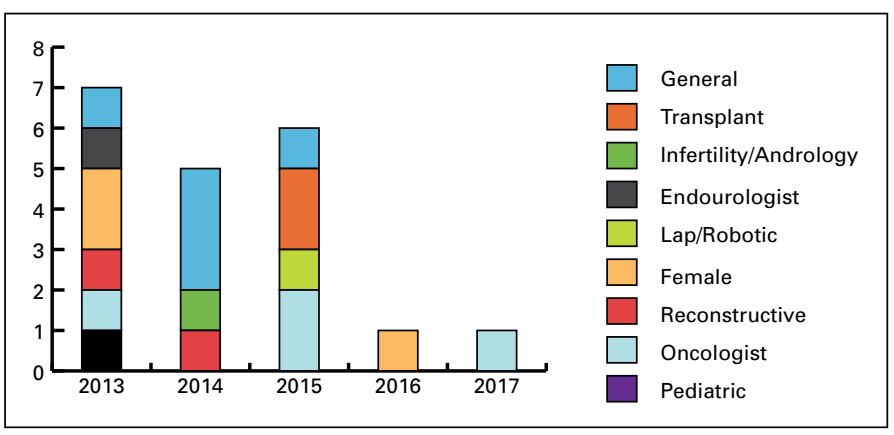

Fig. 3c. Anticipated recruitment needs in the region "Other."

at academic centres throughout Canada. This is not surprising with the aging population, and given the increased incidence of several genitourinary malignancies and/or their high prevalence, particularly given recent advances in surgical and medical treatments. ${ }^{5}$ The need for academic urologists, with increasing specialization, in general is also anticipated to increase in the future; evidence of improved outcomes at high volume centres is likely to sway private practice and community urologists to refer complex patients requiring specialized tertiary care to these high volume academic centres. ${ }^{3}$ In addition, it is imperative that academic institutions promote a proper balance of reserved academic time and clinical practice to maintain quality of research and surgical innovation. It is reassuring that most centres are willing to offer $25 \%$ to $50 \%$ protected time for non-clinical activities (Table 3).

One of the limitations of this survey is that it relies on individual leader's projections, where one formulates a balanced assessment of institutional needs coupled with projections of retirement. As such, one may consider conducting a survey of current practicing urologists in academic institutions to more accurately predict future waves of retirement. Furthermore, multiple other variables, in addition to retirement, are involved in human resource planning, including availability of hospital resources and acceptance of recruits by their respective university administrations. As such, our estimation of recruitment is really an estimate at best, as opposed to actual recruitment.

\section{Conclusion}

A total of 68 urologists covering most subspecialties need to be recruited into academic urology across Canada within the next 5 years. This crucial information can be used to help guide urology residents in choosing the most appropriate fellowship, in addition to providing them with an overview of future job prospects at academic institutions throughout the country.

Acknowledgement: Dr. Wassim Kassouf is a recipient of a Research Scholar Award from the FRSQ.

Competing interests: None declared.

This paper has been peer-reviewed.

\section{References}

1. Taylor DW. Finding Canada's healthcare equilibrium. Healthc Manage Forum 2012;25:48-61. http:// dx.doi.org/10.1016/i.homf.2012.03.003

2. Pace KT, Provan JL, Jewett MAS. The urology workforce in Ontario for the 21 st century: Feast or Famine? Can I Surg 1999;42:181-9

3. Lightfoot AJ, Rosevar HM, Steers WD, et al. Current and future need for academic urologists in the United States. J Urol 201 1;185:2283-7. http://dx.doi.org/10.1016/i.juro.2011.02.058

4. The Canadian Post M.D. Education Registry (CAPER). www.caper.ca. Accessed May 14, 2013.

5. Eheman C, Henley SJ, Ballard-Barbacsh R, et al. Annual report to the nation on the status of cancer, 1975-2008, featuring cancers associated with excess weight and lack of sufficient physical activity. Cancer 2012;118:2338-66. http://dx.doi.org/10.1002/cncr.27514

Correspondence: Dr. Wassim Kassouf, Division of Urology, McGill University Health Centre, 1650 Cedar Ave., Rm L8-315, Montreal, QC H3G 1A4; fax: 514-934-8297; wassim.kassou@muhc.mcgill.ca 